
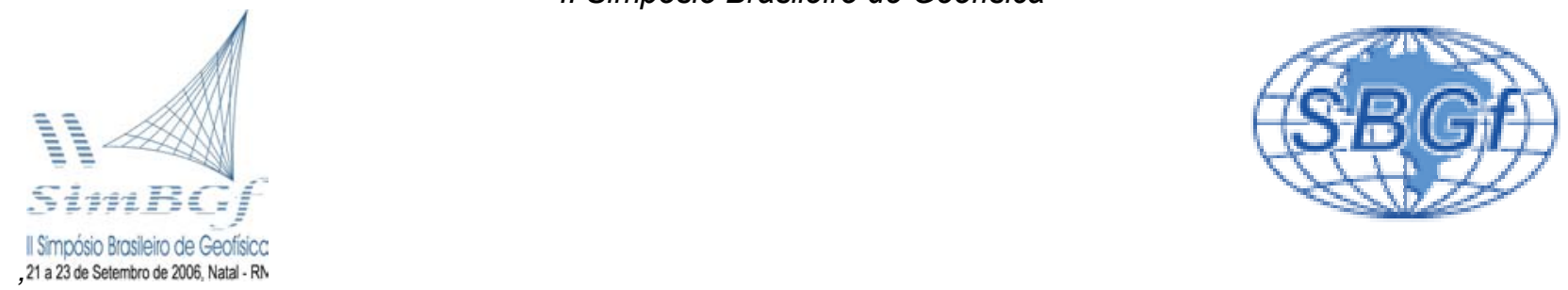

\title{
Sismicidade na área do reservatório de Itá, SC/RS
}

L.C. Ribotta ${ }^{1}$, J.A. Mioto ${ }^{1}$ e J.V.M. Regina ${ }^{2}$

IPT -Instituto de Pesquisas Tecnológicas do Estado de São Paulo S.A. ${ }^{1}$, Tractebel Energia S.A. ${ }^{2}$

Copyright 2004, SBGf - Sociedade Brasileira de Geofisica

Este texto foi preparado para a apresentação no II Simpósio de Geofísica da Sociedade Brasileira de Geofisica, Natal, 21-23 de setembro de 2006. Seu conteúdo foi revisado reprado pela Comissáo Techo-cientica do II SR-SBG mas não necessaniamente representa a opinião da SBGf ou de seus associados. E proibida a reprodução total ou parcial deste material para propósitos comerciais sem prévia autorização da SBG

\section{Resumo}

A UHE de Itá está localizada $\left(27,27^{\circ} \mathrm{S}\right.$ e $\left.52,38^{\circ} \mathrm{W}\right)$ no rio Uruguai, SC/RS, nos basaltos da Formação Serra Geral, Bacia do Paraná, que no nível normal de operação, o reservatório terá $141 \mathrm{~km}^{2}, 5100 \mathrm{~km}^{3}, 145 \mathrm{~km}$ de extensão e $125 \mathrm{~m}$ de profundidade máxima. $\mathrm{O}$ enchimento do reservatório ocorreu entre 13.12.1999 e 23.04.2000. A sismicidade na área apresentou as seguintes características: começou 2 dias após o início do enchimento do lago; foram registrados 13705 sismos até setembro de 2005, magnitude máxima $2,5 \mathrm{M}_{\llcorner}(90 \%$ dos sismos têm $\left.\mathrm{M}_{\mathrm{L}}<0,5\right)$; maior atividade na fase do enchimento e nos primeiros meses de operação do reservatório, seguida de uma diminuição, sugerindo uma provável estabilização; epicentros localizados predominantemente na área do reservatório e aparente concentração em grupos; distribuição temporal dos epicentros mostra correlação com o enchimento; parâmetro b iguais a 2,7 e 3,2 para a relação de freqüência-magnitude simples e cumulativa; e está ocorrendo numa região que apresenta características da existência de tensões residuais de natureza geológica. Este é mais um caso de sismicidade induzida por reservatórios - SIR e de acordo com suas características é do tipo rápida (rapid) ou inicial (initial).

\section{Introdução}

A UHE Itá está localizada $\left(27,27^{\circ} \mathrm{S}\right.$ e $\left.52,38^{\circ} \mathrm{W}\right)$ no rio Uruguai, SC/RS, nos basaltos da Formação Serra Geral, Bacia do Paraná, que no nível normal de operação, o reservatório terá $141 \mathrm{~km}^{2}, 5100 \mathrm{~km}^{3}, 145 \mathrm{~km}$ de extensão e $125 \mathrm{~m}$ de profundidade máxima (CBDB, 2006).

Com a finalidade de detectar a ocorrência de sismos associados ao processo do enchimento do lago foi instalada uma rede sismológica local, como parte dos programas sócio-ambientais desenvolvidos pela Tractebel, com a supervisão do IBAMA, cujas ações e resultados são informados regularmente ao órgão ambiental mediante a emissão de relatórios técnicos (Tractebel, 2003).

\section{Resenha sobre sismotectônica para o projeto de Itá}

Para composição do quadro sismotectônico regional foram considerados os resultados de interpretação regional de estruturas geológicas, a partir de anomalias geofísicas profundas (gravimetria, magnetometria e geotermia), e daqueles obtidos por interpretação fotogeológica nas mais diversas escalas.

Orientações aeromagnéticas foram sugeridas alinhadas ao curso do rio Uruguai, numa possível conexão ao lineamento oceânico de Florianópolis (Zona de Falha Rio Uruguai: Araújo et al., 1995); anomalias gravimétricas mostram possíveis descontinuidades secundárias; indicações de fluxo geotérmico nas imediações dos projetos hidrelétricos Itá e Machadinho são próximas de valores de áreas de embasamento cristalino. Estas observações foram integradas àquelas de interpretação fotogeológica e levantamentos expeditos de campo para o Empreendimento Hidrelétrico Itá (IPT, 2002).

A partir da análise de vários fatos, destacando-se: ocorrências de lineamentos interpretados a partir de anomalias geofísicas profundas, distribuição de estruturas geológicas em sistemas que condicionaram processos geológicos regionais ao longo do tempo, feições de mobilidade nas estruturas geológicas em tempos mais recentes, e identificação de tensões contemporâneas nos maciços rochosos da escavação (Infanti et al., 1999), até mesmo com determinação de seus módulos nos maciços da fundação das estruturas civis e hidráulicas, a área do Empreendimento de Itá tem possibilidade de manifestação de instabilidade pelo enchimento do seu reservatório.

$\mathrm{Na}$ análise das falhas quanto às direções dos esforços envolvidos, os resultados indicaram direção regional de $\sigma_{1}$ de NE-SW/suborizontal e de $\sigma_{3}$ de NW-SE/suborizontal, concordantes com o posicionamento das falhas dextrais e sinistrais. Contudo, a idade do movimento tectônico ainda não foi estabelecida.

Observando os resultados dos estudos de Zalán et al. (1987), Quintas (1995), Paiva Filho (2000), Artur e Soares (2002) dentre outros, de todas as descontinuidades regionais destacam-se aquelas orientadas a SW-NE (Zona de Falha Lancinha-Cubatão), refletindo possível inflexão nos conjuntos das rochas do embasamento e da Bacia do Paraná. Esta zona de falha, encurvada, praticamente alcança a área, orientada pelas localidades de Erechim, Marcelino Ramos (SW), Lacerdópolis e Tangará (NE). A pesquisa de Paiva Filho corrobora esta diversidade de estruturas, considerando o Alinhamento do Rio Uruguai (SW-NE e subparalelo à Zona de Falha Lancinha-Cubatão), interceptando faixas estruturais orientadas a NW-SE (zonas de transcorrências Torres-Posadas, Chapecó-Cacique Doble e Xanxerê-Campos Novos).

A reincidência de movimentação de fraturas do embasamento conforme sugeriram os estudos conduzidos em 1987 pode ser estendida até os dias atuais, em observação ao contínuo deslocamento relativo da Placa SulAmericana em relação às de Nazca e do Caribe. A libe- 
ração de energia de deformação, quer naturalmente (sismos de Blumenau, Caxias do Sul, ...) quer por intervenção antrópica (reservatórios), referendam a existência de um quadro de tensões contemporâneo na área.

\section{Sismicidade regional}

Com base no Catálogo de Sismos Brasileiros e regiões vizinhas foi verificada a ocorrência de sismos dentro de um raio de $300 \mathrm{~km}$ do eixo da barragem, cujos epicentros são mostrados na Figura 1, que também mostra as localizações das estações sismológicas que estão ou estiveram em funcionamento na região.

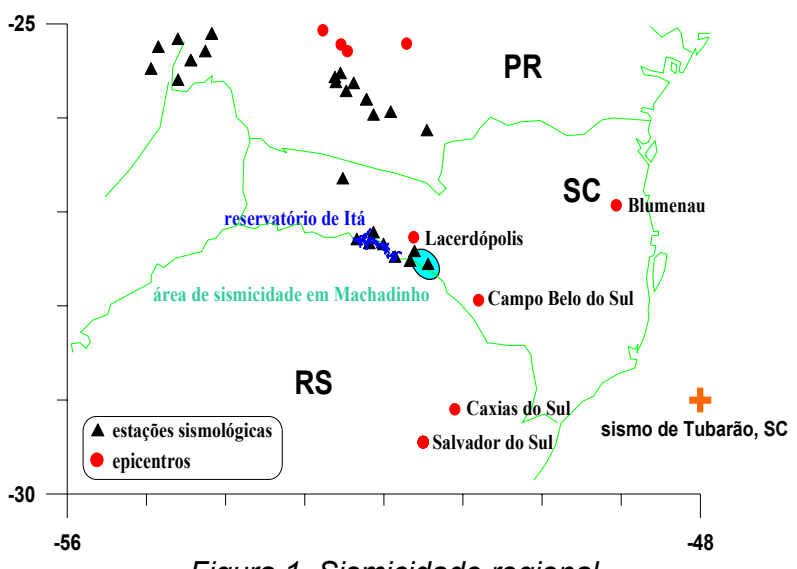

Figura 1. Sismicidade regional.

Com distância epicentral menor do que $100 \mathrm{~km}$ do empreendimento têm os sismos ocorridos em Campo Belo do Sul (28.07.1989, 1,2 mR, IV-V MM) e em Lacerdópolis (13.05.2001, 1,4 mR, III MM). Na pesquisa, destaca-se as séries de eventos com epicentros em Salvador do Sul (1974, 1,2 $\mathrm{m}_{\mathrm{R}}$ e IV MM) e Caxias do Sul (1984, 2,2 mR e V-VI MM). Os outros eventos registrados têm magnitudes variando entre 1,2 e 2,2 $m_{R}$, excetuando-se o de Blumenau, de 1898, com magnitude estimada em 3,9 m.

Em 28.06.1939, ocorreu um sismo na Plataforma Continental (Tubarão, SC; epicentro indicado na Figura $1 \mathrm{com}$ um "+"), 5,5 mb, distante $470 \mathrm{~km}$, que, de acordo com Berrocal et al. (1984), na área do empreendimento a intensidade macrossísmica atingiu IV MM.

Com o monitoramento sismológico na área do reservatório de Machadinho (vide item 4) foi caracterizada uma atividade sísmica local associada com o enchimento do lago, com eventos de magnitudes muito baixas (menores do que $1,8 \mathrm{M}_{\mathrm{L}}$, predominando as negativas), cuja área epicentral está indicada na Figura 1 (IPT, 2005).

Os dados mostram que na área ocorreram eventos naturais e induzidos de pequena magnitude e intensidades médias.

\section{Monitoramento sismológico local}

O início do monitoramento na região teve início na segunda metade da década de 1970, com a instalação de estações no entorno de reservatórios, tais como: Itaipu, Foz do Areia, Salto Santiago e Segredo.

Entre 1990 e 1999, o monitoramento local foi efetuado por meio da Estação IT1, com registro analógico em papel enfumaçado e sismômetro de período curto e componente vertical, instalada nas proximidades da futura barragem do reservatório de Itá (UnB, 1998).

A partir de 13.11.1999, o monitoramento foi efetuado por uma rede com cinco estações instaladas no entorno do reservatório de Itá, compostas por registradores digitais, sismômetros triaxiais de período curto, GPS e sistema de alimentação por painel solar e baterias. Para monitorar a fase durante e após o enchimento do reservatório de Machadinho foram transferidas três estações da área de Itá (IT4, IT5 e IT9) em 30.06.2001. Em função da sismicidade em Itá, em 30.10.2002 foi reinstalada a Estação IT9 (IPT, 2003).

Atualmente, na área do reservatório de Machadinho e no entorno dos reservatórios de Barra Grande (rio Pelotas, SC/RS) e Campos Novos (rio Canoas, SC), situados logo a montante de Machadinho, estão em operação três e quatro estações, respectivamente (IPT, 2005).

\section{Sismicidade na área do reservatório de Itá}

Os sismos na área do reservatório foram registrados, em sua grande maioria apenas por uma das estações da rede sismológica. Assim, as coordenadas dos epicentros foram determinadas, matematicamente, conhecendo-se a distância epicentral (fórmula de Omori, apud NEUMANN, 1970 , com K = 6,7 km/s) e o azimute (WILLMORE, 1979). Para quantificar os sismos, adotou-se a relação obtida por RICHTER (1958) para determinar a magnitude local $M_{L}$ e a energia sísmica liberada $E$.

A atividade sísmica na área do reservatório de Itá teve início em 15.12.1999 com epicentros próximos da barragem e se estendendo em direção ao remanso do reservatório, como mostra a Figura 2., onde foram registrados 13705 sismos até setembro de 2005 , nos primeiros $70 \%$ do lago e com uma aparente concentração em grupos.

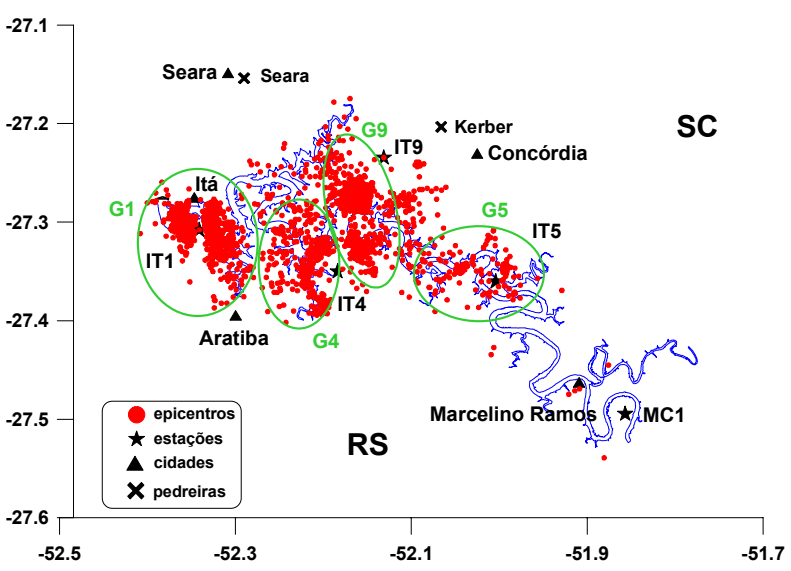

Figura 2. Distribuição epicentral.

Adotando-se os grupos de epicentros indicados na Figura 2 foram construídas as distribuições temporais diárias do número de eventos e da energia liberada (tamanho dos eventos) mostradas na Figura 3 , com a variação do nível d'água do reservatório. $\mathrm{O}$ enchimento do lago iniciou em 13.12.1999 e atingiu o seu nível de operação em 23.04.2000. Os primeiros eventos no G1, G4, G9 e G5 fo- 


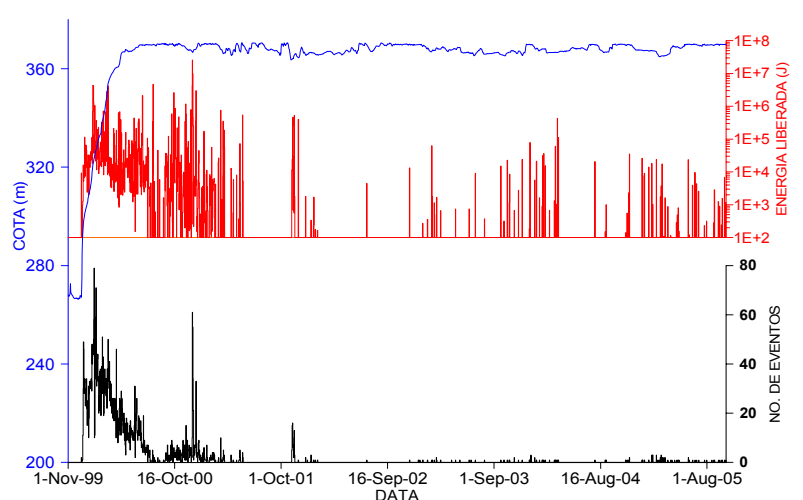

a) grupo 1

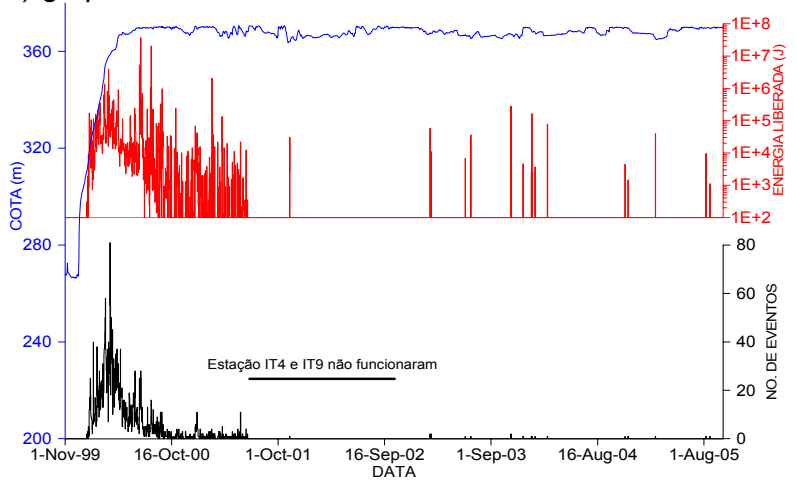

b) grupo 4

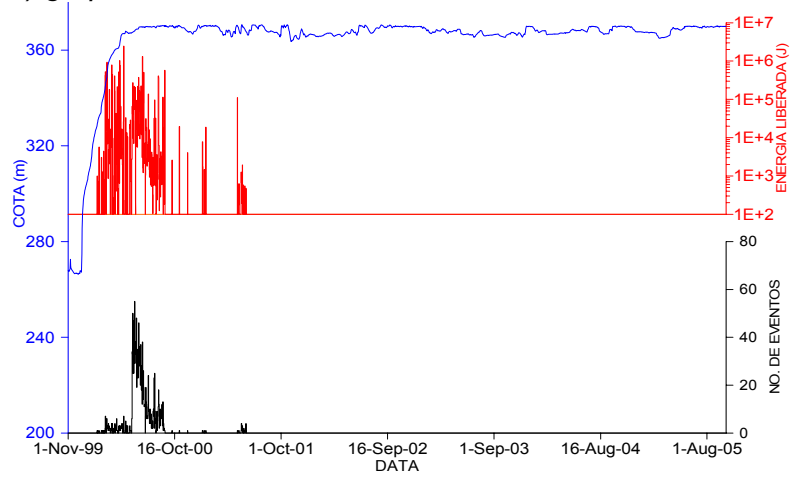

c) grupo 5

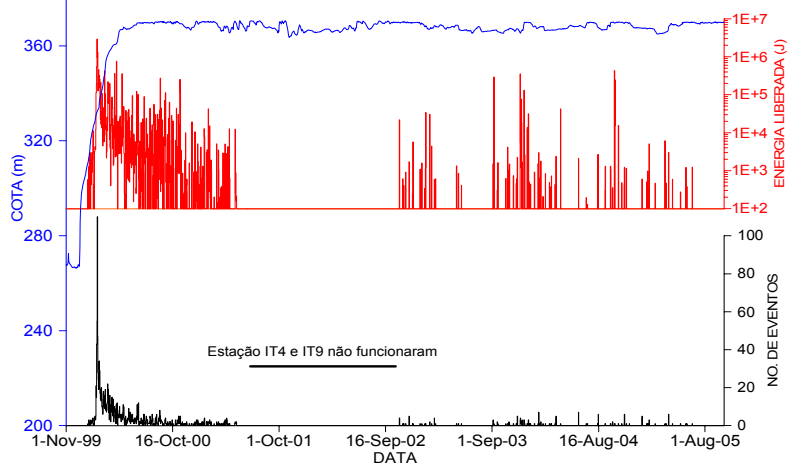

d) grupo 9

Figura 3. Distribuição temporal para os grupos. ram registrados, respectivamente, em 15.12.1999, 12.01, 15.01 e 05.02.2000,. Cada grupo mostra um comportamento temporal diferenciado. A sismicidade teve uma maior atividade durante a fase de enchimento e nos primeiros meses de operação normal do reservatório, seguida de uma diminuição. Problemas operacionais da Estação IT5 dificultam caracterizar adequadamente o início da sismicidade no G5.

$\mathrm{O}$ valor do parâmetro $\underline{b}$ da relação de freqüência-magnitude definida por Gutemberg e Richter em 1954 é um dos parâmetros utilizados nos estudos para caracterizar se a sismicidade registrada é induzida pelo reservatório (Gupta e Rastogi, 1976 e Gupta, 1992). A Figura 4 apresenta os resultados obtidos considerando os sismos pertencendo a um único grupo. Berrocal et al. (1996) obteve para a região sudeste brasileira (entre os paralelos $15^{\circ} \mathrm{S}$ $32^{\circ} \mathrm{S}$ e os meridianos $35^{\circ} \mathrm{W}-52^{\circ} \mathrm{W}$ ) os valores de $\underline{b}, 1,06$ e 1,65 , para a relação de freqüência-magnitude simples $e$ cumulativa, respectivamente.

A distribuição das magnitudes mostra o predomínio dos valores pequenos $\left(90 \%\right.$ dos sismos têm $\left.M_{L}<0,5\right)$ e que a magnitude máxima foi de $2,5 \mathrm{M}_{\mathrm{L}}$.

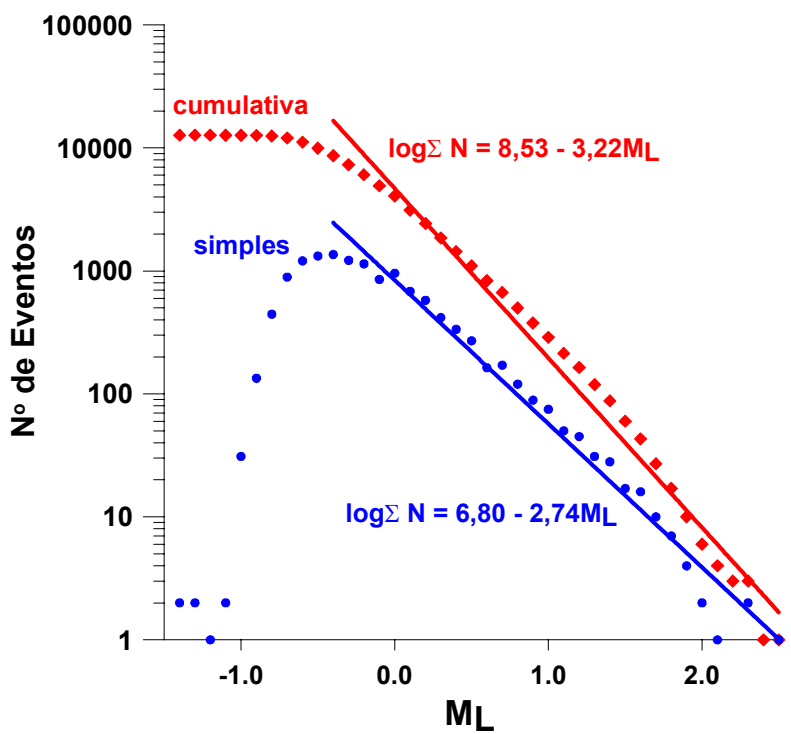

Figura 4. Relação freqüência-magnitude.

\section{Conclusões}

A atividade sísmica na área do reservatório de Itá apresentou as seguintes características: começou 2 dias após o início do enchimento do lago; teve uma maior atividade durante a fase de enchimento e nos primeiros meses de operação do reservatório, seguida de uma diminuição, sugerindo uma provável estabilização; epicentros localizados predominantemente na área do reservatório e aparente concentração em grupos; a distribuição temporal dos epicentros mostra correlação com o processo de enchimento do lago; os valores do parâmetro $b$ são maiores do que aqueles obtidos para a sismicidade natural da região; e está ocorrendo numa região que apresenta características da existência de tensões residuais de natureza geológica. 
De acordo com as características básicas de sismicidade induzida por reservatórios - SIR, apresentada e discutida por diversos autores, tais como: Gupta e Rastogi (1976), Gupta (1992), Gomide (1999), Marza et. al. (1999) e Assumpção et al. (2002), dentre outros, pode-se afirmar que a sismicidade registrada na área do reservatório de Itá é mais um caso de SIR e que, de acordo com Simpson, 1988 e Talwani, 1995 e 1997 (apud Assumpção et al., 2002) é do tipo rápida (rapid) ou inicial (initial), respectivamente.

\section{Agradecimentos}

Agradecemos à Tractebel Energia S.A. pela permissão de publicar estes dados. Especial agradecimento a Luis Bennemann, da Epagri e a João Geraldo Toaldo, da Tractebel, pelos trabalhos desenvolvidos na instalação das estações e coletas periódicas dos dados e a Josué Rodrigues Fischer e Aroldo Ribeiro da Silva, do IPT, pela cooperação na análise dos dados.

\section{Referências}

ARAÚJO, L. M., FRANÇA, A. B. \& POTTER, P. E. 1995. Aqüifero gigante do Mercosul no Brasil, Argentina, Uruguai e Paraguai. UFPR/Petrobrás. Avulso-16 p-9 anexos. Curitiba, PR.

ARTUR, P. C. \& SOARES, P. C. 2002. Paleoestruturas e petróleo na Bacia do Paraná, Brasil. Rev. Bras. Geoc., 32(4): 433-448.

ASSUMPÇÃO, M., MARZA, V., BARROS, L., CHIMPLIGANOND, C., SOARES, J. E., CARVALHO, J., CAIXETA, D., AMORIM, A. \& CABRAL, E. 2002. Reservoirinduced seismicity in Brazil. Pure Appl. Geophys., 159: 597-617.

BERROCAL, J., ASSUMPÇÃO, M., ANTEZANA, R., DIAS NETO, C. M., ORTEGA, R., FRANÇA, H. \& VELOSO, J. V. A. 1984. Sismicidade do Brasil. IAG/USPCNEN, São Paulo, SP. 320 p.

BERROCAL, J., FERNANDES, C., BASSINI, A. \& BARBOSA, J. R. 1996. Earthquake hazard assessment in southeastern Brazil. Geofísica Internacional, 35(3): 257272.

CBDB - COMITE BRASILEIRO DE BARRAGENS. 2006. Catálogo de barragens. Disponível em: www.cbdb.org.br. GOMIDE, L. C. 1999. Nature and History of Reservoir Induced Seismicity in Brazil. Dissertação de Mestrado, Departamento de Ciência Geológica, Universidade da Carolina do Sul, EUA. 60 p.

GUPTA, H. K. 1992. Reservoir-Induced earthquakes. Developmensts in Geotechnical Engineering n 64, Elsevier. 364 p.

GUPTA, H. K. \& RASTOGI, B. K. 1976. Dams and Earthquakes. Elsevier. 229 p.

INFANTI, N., TASSI, P.A., MAZZUTTI, R., PILLER, M. \& MAFRA, J.M.Q. 1999. Tensões residuais nas obras subterrâneas da UHE Itá. In: XXIII Seminário Nacional de Grandes Barragens. Anais. 2: 417-426.

INSTITUTO DE PESQUISAS TECNOLÓGICAS DO ESTADO DE SÃO PAULO. 2002. Análise dos registros da Rede Sismológica de Itá/Machadinho, SC/RS, do período de $1^{\circ}$ de janeiro a 30 de junho de 2000. São Paulo, SP. DIGEO, 288 p. (IPT, Relatório, 58 971).

INSTITUTO DE PESQUISAS TECNOLÓGICAS DO ESTADO DE SÃO PAULO. 2003. Observação das condições sismológicas. In: Tractebel Energia. Atividades ambientais e sócio-patrimoniais; Usina Hidrelétrica Itá. Florianópolis, SC. Seção 1, Meio físico, p. 33-40.

INSTITUTO DE PESQUISAS TECNOLÓGICAS DO ESTADO DE SÃO PAULO. 2005. Acompanhamento das condições sismológicas. In: Consórcio Machadinho. Licença ambiental de operação; LO $n^{\circ}$ 160/2001; renovação; Usina Hidrelétrica Machadinho. Florianópolis, SC. Seção 1, Meio físico, p. 23-28.

MARZA, V. I., BARROS, L. V., SOARES, E. P., CAVALHO, J. M., FONTENELE, D. P., CHIMPLIGANOND, C. N., CAIXETA, D., GOMES, I. P., FURTADO, G. O., CARIM, A. L., SOUZA, G. F., CALIMAN, E. H. \& BARROS, J. B. 1999. Aspectos da sismicidade induzida por reservatórios no Brasil. In: XXIII Seminário Nacional de Grandes Barragens. Belo Horizonte, MG. Anais. 1: 199-211.

NEUMANN, F. 1970. Principios fundamentales para la interpretación de sismogramas. CERESIS, Lima, Peru. $74 \mathrm{p}$.

PAIVA FILHO, A. 2000. Estratigrafia e Tectônica do nível de Riodacitos Pórfiros da Formação Serra Geral. Tese de Doutoramento, Instituto de Geociências e Ciências Exatas, Universidade Estadual Julio de Mesquita Filho - UNESP, Rio Claro, SP. 2 v., 183 p.

QUINTAS, M. C. L. 1995. O Embasamento da Bacia do Paraná: reconstrução geofísica de seu arcabouço. Tese de Doutoramento, Instituto Astronômico e Geofísico, Universidade de São Paulo-USP, São Paulo, SP. 213 p.

RICHTER, C. F. 1958. Elementary Seismology. W. H. Freeman, San Francisco, USA. 768 p.

SIMPSON, D. W., LEITH, W. S. \& SCHOLZ, C. H. 1988. Two types of reservoir-induced seismicity. BSSA, 78(6): 2025-2040.

TALWANI, P. 1995. Two categories of reservoir induced seismicity. In: Int. Symp. on reservoir Induced Seismicity (ISORIS'95). Proc. p. 44-64.

TALWANI, P. 1997. On the nature of reservoir-induced seismicity. Pure Appl. Geophys., 150: 473-492.

TRACTEBEL. 2003. Introdução. In: Tractebel Energia. Atividades ambientais e sócio-patrimoniais; Usina Hidrelétrica Itá. Florianópolis, SC. p.5.

UNIVERSIDADE DE BRASÍLIA. 1998. Estação Sismográfica ITÁ - período janeiro-dezembro 1997. Brasília, DF. 40 p. (Convênio FUB/ELETROSUL, Relatório).

WILLMORE, P. L. 1979. Manual of Seismological Observatory Practice. World Data Center a for Solid Earth Geophysics - Report SE-20, Colorado, USA. 161 p.

ZALÁN, P. V., WOLFF, S., CONCEIÇÃO, J. C. J., ASTOLFI, M. A. M., VIEIRA, I. S., APPI, V. T. \& ZANOTTO, O. A. 1987. Tectônica e sedimentação da Bacia do Paraná. In: SBG, Núcleo Sul, Simpósio Sul-Brasileiro de Geologia, 3. Atas.1: 441-473. 